\title{
The Effects of Organic Certification on Shoppers' Purchase Intention Formation in Taiwan: A Multi-Group Analysis of Structural Invariance
}

\author{
Ming Liu
}

check for updates

Citation: Liu, M. The Effects of Organic Certification on Shoppers' Purchase Intention Formation in Taiwan: A Multi-Group Analysis of Structural Invariance. Sustainability 2022, 14, 55. https://doi.org/ $10.3390 /$ su14010055

Academic Editor: Mario D’Amico

Received: 21 November 2021

Accepted: 20 December 2021

Published: 21 December 2021

Publisher's Note: MDPI stays neutral with regard to jurisdictional claims in published maps and institutional affiliations.

Copyright: (C) 2021 by the author. Licensee MDPI, Basel, Switzerland. This article is an open access article distributed under the terms and conditions of the Creative Commons Attribution (CC BY) license (https:// creativecommons.org/licenses/by/ $4.0 /)$.
Department and Graduate School of Tourism Management, Chinese Culture University, Taipei 11114, Taiwan; lm2@ulive.pccu.edu.tw; Tel.: +886-2-2861-0511 (ext. 35732/35701); Fax: +886-2-2861-1402

\begin{abstract}
Labeling products with organic certification logos is a means of indicating to consumers that those products are government certified. However, in Taiwan, organic certification is not required before a food product claims itself organic. Since previous research showed that the COVID-19 lockdown effected both Spanish and Romanian subjects' intention to purchase more sustainable products, the aim of this study was to determine whether the perception of organic certification labeling makes a difference in how organic shoppers' purchasing intentions toward organic produce were realized. Data from organic produce shoppers were used to identify organic certification labeling differences. One group of shoppers was asked about their purchase behaviors toward governmentcertified organic produce labeled with the certification logo $(N=468)$, while the other was asked about their purchase behaviors toward self-claimed organic produce without a government certification logo $(N=403)$. Multi-group structural equation modeling (SEM) techniques were employed as the main method of analysis in this study. The results indicated that the hypothesized model was validated. In addition, through this process, it was clarified that this government organic certification labeling significantly enhances the influence of organic produce shoppers' behavioral beliefs regarding organic produce on their attitudes.
\end{abstract}

Keywords: organic certification; purchase intention; subjective knowledge; theory of reasoned action

\section{Introduction}

Food shoppers search for specific information on the foods and beverages that they purchase in the hopes that further information will help them in making purchasing decisions [1]. Previous food studies have indicated that product information affects consumers hedonic judgments and sensory perceptions [1-5]. Among these attributes, aspects of food quality such as external appeal, taste, freshness, and safety have become crucial features that are valued by consumers [6,7]. Other extrinsic variables have also been studied, including production-related variables such as manufacturing processes, fair trade, and the origin of production [8,9]. Credence characteristics play an important role in the present food marketing system. Organic certification lends credence to the production means of organic produce [5]. Providing such information has been shown to generate a positive effect on consumer preferences $[3,5,8,10]$. Moreover, since distrust of the conventional food supply system influences consumer food choices [1], organic products are gaining popularity.

The COVID-19 pandemic, declared by the World Health Organization on 11 March 2020, is challenging the world [11-15]. Studies showed that outbreaks have triggered perceived risk in food purchasing behaviors [8,11-15]. Organic logos play a major role in notifying consumers that a product is "organic" [16-18]. Labels are extrinsic cues that help consumers form expectations regarding product quality, influencing consumer attitudes and behaviors in buying products [18-22]. Taiwan has applied labeling regulations for organic agricultural products including rice, vegetables, fruits, and tea since 2009. An updated version was presented in 2019 in response to the concerns raised by the public 
to reinforce the authentication mechanism for certifying organic foods [23-25]. Farmers can apply organic labels from government-accredited certification organizations [16]. As Taiwan is one of the top-performing OECD members in reading literacy, mathematics, and sciences [26], it is of interest to determine whether knowledge exerts effects on consumers' organic food purchase intention.

Therefore, based on the model derived from the Theory of Reasoned Action (TRA) [27] in association with the construct of subjective knowledge, the aim of this study was to determine whether this organic certification labeling makes a difference in how organic food shoppers' subjective knowledge, attitudes, and purchase intentions toward organic produce (i.e., fruits and vegetables) are realized. The contribution of this study consists of a theoretical understanding backed by empirical results. The results contribute to a more comprehensive understanding of the role that organic food certification labeling plays in influencing organic food shoppers' behaviors in food systems.

\section{Literature Review}

\subsection{Organic Certification Labeling in Taiwan}

Since 2009, Taiwan has applied labeling regulations for organic agricultural products. The implementation of the Agricultural Production and Certification Act (APCA) requires that growers be certified by a third party before they can legally claim that their produce is organic [16]. However, this Taiwan government labeling regulation is not mandatory for all organic products [20-22]. A previous study showed that farm operators who participated in different organizational groups tend to adopt different agricultural product certifications, including Good Agricultural Practices (GAP), Traceable Agriculture Products (TAP), and Organic Agricultural Products [20,22]. Consumers remained skeptical about the myriad of organic products in the market. Among the concerns raised by the public are questions originating from inconsistent figures on pesticide imports, organic food imports, and the fast growth of domestic organic farmland [23,24]. In 2019, an updated version, the Organic Agriculture Promotion Act (OAPA) [25], was presented in response to the concerns raised by the public to reinforce the authentication mechanism for certifying organic foods $[12,18,19]$. The organic certification label is shown in Figure 1.

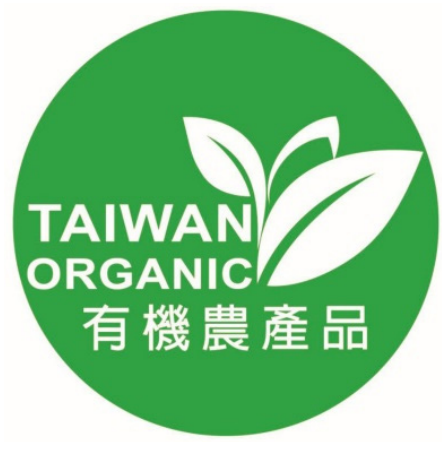

Figure 1. Taiwan CAS organic agricultural product label.

\subsection{Theory of Reasoned Action}

The Theory of Reasoned Action (TRA) [26], developed by Martin Fishbein and Icek Ajzen, has been applied in several food behavior studies [28-31]. The TRA suggests that a person's behavior is driven by their intentions. Individuals' intentions are further driven by personal and social factors such as attitudes toward particular behaviors and subjective norms. Attitudes are further influenced by behavioral beliefs [27]. Instead of just making predictions regarding behavior, the TRA enables researchers to further understand how, and under what circumstances, people make decisions related to food-selection behaviors [28-31]. Beliefs are the underlying characteristics, qualities, and attributes associated with an object or behavior of interest that determine a person's good or bad attitudes regarding the object or behavior. Beliefs can be inferred or formed from observations and 
information. They can change, persist, be forgotten, or be replaced with new beliefs [27]. Behavioral beliefs link the behavior of interest to expected outcomes. An attitude toward a behavior reflects a person's overall evaluation of performing the behavior of interest. An intention indicates a person's readiness to perform a given behavior and is the immediate precursor of that behavior [27].

Certain studies have examined consumer purchase and consumption behaviors toward organic food products, including perceptions of organic foods, factors that facilitate or prevent organic food choices, and the attitudes and reasons for the purchase or nonpurchase of organic food products [29-39]. Results have shown that consumers typically perceive organically grown food as being more flavorful than conventional food [26]. Perceived health benefits and a desire for safe food are the primary reasons behind consumer interest in organically grown foods [3,27-38]. Consumers who choose organic food seek to protect their bodies from pesticides, hormones, antibiotics, chemicals, and genetically modified organisms (GMOs). Other studies have suggested that the increased popularity of organic food products could be linked to broader concerns about environmental issues and the ethical treatment of animals $[20,21,36]$.

\subsection{Subjective Knowledge}

Three types of knowledge exert effects on consumer decisions: Previous product experience, objective product knowledge, and subjective product knowledge. Experience is related positively to objective knowledge and subjective knowledge [40,41]. Objective product knowledge can be evaluated by assessing a person's cognitive or functional knowledge, whereas subjective product knowledge measures what consumers think they know about the product $[4,30,33]$. Previous studies have investigated the relationships among knowledge, attitude formation, and behavior. A person who possesses a high level of product knowledge has increased confidence in making behavioral decisions, which results in making him or her more likely to engage in the behavior in question. However, studies have reported weak to moderate correlations between subjective and objective knowledge $[4,30,33]$. What people think they know does not strongly match with what they actually know. Pieniak et al. [4] and Aertsens et al. [41] investigated the association between consumer subjective knowledge, objective knowledge, and general attitudes toward organic food and organic vegetable consumption in Belgium. The results showed that subjective knowledge exhibited a direct association with organic vegetable consumption, whereas objective knowledge was only indirectly associated with organic vegetable consumption.

Based on the above discussion, this study proposes the following hypotheses as a means of identifying whether this government organic certification labeling makes a difference in how consumers' subjective knowledge, attitudes, and purchase intentions toward organic produce (i.e., fruits and vegetables) are realized. Hypotheses 1 through 5 focus on the dynamics of how subjective knowledge affects consumer behaviors toward organic fruits and vegetables and certification-labeled organic fruits and vegetables [12-15]. Hypothesis 6 focuses on identifying whether government organic certification labeling makes a difference in how consumers' subjective knowledge, attitudes, and purchase intentions toward organic produce are realized [19-22].

Hypothesis H1a. Shoppers' subjective knowledge of organic fruits and vegetables positively influences their behavioral beliefs regarding them.

Hypothesis H1b. Shoppers' subjective knowledge of certification labeled organic fruits and vegetables positively influences their behavioral beliefs regarding them.

Hypothesis H2a. Shoppers' subjective knowledge of organic fruits and vegetables positively influences their attitudes toward their purchase of them.

Hypothesis H2b. Shoppers' subjective knowledge of certification labeled organic produce positively influences their attitudes toward their purchase of them. 
Hypothesis H3a. Shoppers' subjective knowledge of organic fruits and vegetables positively influences their purchase intentions toward them.

Hypothesis H3b. Shoppers' subjective knowledge of certification labeled organic fruits and vegetables positively influences their purchase intentions toward them.

Hypothesis H4a. Shoppers' behavioral beliefs regarding organic fruits and vegetables positively influence their attitudes toward their purchase of them.

Hypothesis H4b. Shoppers' behavioral beliefs regarding certification labeled organic fruits and vegetables positively influence their attitudes toward their purchase of them.

Hypothesis H5a. Shoppers' attitudes toward their purchasing of organic fruits and vegetables positively influence their purchase intentions toward them.

Hypothesis H5b. Shoppers' attitudes toward their purchasing of certification labeled organic fruits and vegetables positively influence their purchase intentions toward them.

Hypothesis H6. The causal relationships among subjective knowledge, behavioral beliefs, attitudes, and purchase intentions are variant across organic shoppers with or without organic certification labeling.

Hypothesis H6-1. The causal relationship between subjective knowledge and behavioral beliefs is variant across organic shoppers with or without organic certification labeling.

Hypothesis H6-2. The casual relationship between subjective knowledge and attitudes is variant across organic shoppers with or without organic certification labeling.

Hypothesis H6-3. The casual relationship between subjective knowledge and purchase intentions is variant across organic shoppers with or without organic certification labeling.

Hypothesis H6-4. The casual relationships between behavioral beliefs and attitudes are variant across organic shoppers with or without organic certification labeling.

Hypothesis H6-5. The casual relationships between attitudes and purchase intentions are variant across organic shoppers with or without organic certification labeling.

Based on the above discussion, this study hypothesizes the conceptual model shown in Figure 2 below.

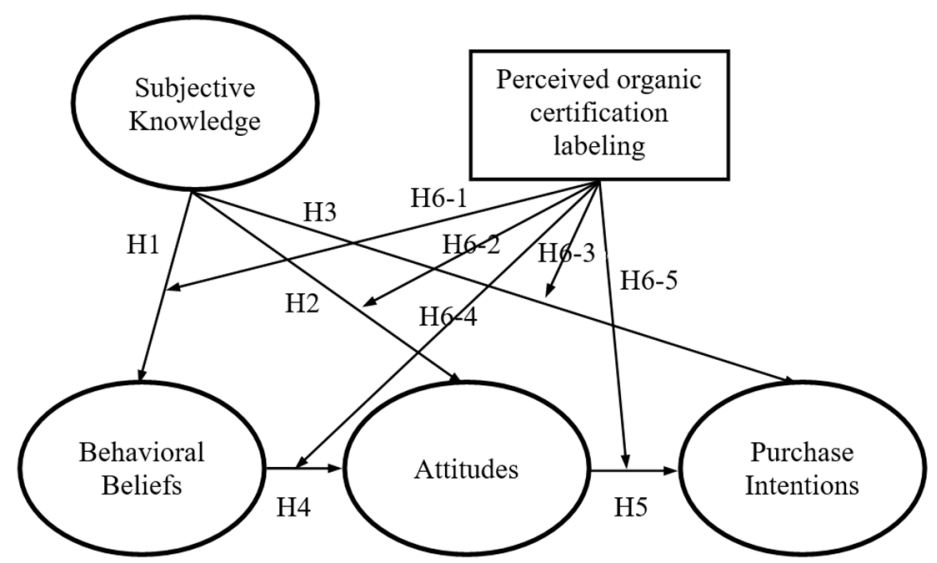

Figure 2. Proposed conceptual model. 


\section{Materials and Methods}

This paper reports the analysis of data collected from organic food shoppers. Based on their purchased organic produce (whether labeled with government organic certification or not), one group of shoppers was asked about their purchase behaviors toward certification-labeled organic produce (i.e., fruits and vegetables) in all questions with the government label shown. The other group of shoppers was just asked about their purchase behaviors toward organic produce in general. A field survey approach was adopted to achieve the stated research purposes. Quantitative data collected from this study were analyzed using structural equation modeling (SEM) for model testing. SEM is a statistical technique combining multiple regression and factor analysis to estimate a series of relationships between interrelated variables simultaneously [42]. In addition, multi-group invariance analyses [43] were performed to compare the findings from two groups of organic food shoppers.

\subsection{Participants and Procedures}

A total of 871 effective surveys were collected through a self-administrated structured questionnaire. Amongst those, based on their purchased organic produce (whether labeled with government organic certification or not), 468 participants were asked about government certification-labeled organic produce and 403 were asked about self-claimed organic produce. To collect the data, we contacted and visited organic food specialty stores to ask their permission to conduct the survey in their stores. These selected organic food specialty stores are registered with the Council of Agriculture. Trained fieldworkers introduced organic food shoppers to the purpose of the study, provided an estimate of the amount of time required to complete the questionnaire, and asked whether the shoppers had an interest in filling out the survey. Shoppers were also informed about the level of confidentiality associated with their participation. Detailed demographic characteristics of the respondents in this study are presented in Table 1.

Table 1. Demographic characteristics of the respondents.

\begin{tabular}{|c|c|c|c|c|c|c|}
\hline & \multicolumn{2}{|c|}{ All } & \multicolumn{2}{|c|}{ Labeled Organic } & \multicolumn{2}{|c|}{ Organic } \\
\hline & $\begin{array}{c}\text { Frequency } \\
(N=871)\end{array}$ & $\begin{array}{c}\text { Percentage } \\
(\%)\end{array}$ & $\begin{array}{c}\text { Frequency } \\
(N=468)\end{array}$ & $\begin{array}{c}\text { Percentage } \\
(\%)\end{array}$ & $\begin{array}{l}\text { Frequency } \\
(N=403)\end{array}$ & $\begin{array}{c}\text { Percentage } \\
(\%)\end{array}$ \\
\hline \multicolumn{7}{|l|}{ Gender } \\
\hline Male & 369 & 42.4 & 219 & 46.8 & 150 & 37.2 \\
\hline Female & 502 & 57.6 & 249 & 53.2 & 253 & 62.8 \\
\hline \multicolumn{7}{|l|}{ Age } \\
\hline 20 and less & 30 & 3.4 & 22 & 4.7 & 8 & 2.0 \\
\hline $21-30$ & 419 & 48.1 & 313 & 66.9 & 106 & 26.3 \\
\hline $31-40$ & 132 & 15.2 & 56 & 12.0 & 76 & 18.9 \\
\hline $41-50$ & 136 & 15.6 & 41 & 8.8 & 95 & 23.6 \\
\hline 51 and above & 154 & 17.7 & 36 & 7.7 & 118 & 29.3 \\
\hline \multicolumn{7}{|l|}{ Education } \\
\hline Junior High & 36 & 4.1 & 15 & 3.2 & 21 & 5.2 \\
\hline Senior High & 165 & 18.9 & 50 & 10.7 & 115 & 28.5 \\
\hline College & 140 & 16.1 & 54 & 11.5 & 86 & 21.3 \\
\hline University & 427 & 49.0 & 299 & 63.9 & 128 & 31.8 \\
\hline Postgraduate & 103 & 11.8 & 50 & 10.7 & 53 & 13.2 \\
\hline \multicolumn{7}{|c|}{ Monthly Income (NTD) } \\
\hline$\leq 20,000$ & 327 & 37.5 & 295 & 63.0 & 32 & 7.9 \\
\hline $20,001-40,000$ & 277 & 31.8 & 100 & 21.4 & 177 & 43.9 \\
\hline $40,001-60,000$ & 154 & 17.7 & 46 & 9.8 & 108 & 26.8 \\
\hline $60,001-80,000$ & 61 & 7.0 & 14 & 3.0 & 47 & 11.7 \\
\hline $80,001-100,000$ & 29 & 3.3 & 6 & 1.3 & 23 & 5.7 \\
\hline$\geq 100,000$ & 23 & 2.6 & 7 & 1.5 & 16 & 4.0 \\
\hline
\end{tabular}


Of the total 871 participants in this study, the majority of the respondents $(57.6 \%)$ were women. In terms of age, the largest percentage of the respondents (41.3\%) was aged 19-25 years old. Furthermore, almost half of the respondents (49\%) had a bachelor's degree.

\subsection{Measures}

A questionnaire consisting of three sections was used to collect data. The constructs were measured with previously validated scales following prior studies $[4,27,44,45]$ as shown in Table 2 . The first section probed the four variables included in the proposed empirical model (i.e., subjective knowledge, behavioral beliefs, attitudes, and intentions). Variable attributes were measured on a five-point Likert scale ( $1=$ strongly disagree; $5=$ strongly agree). The second section measured demographic characteristics (i.e., gender, age group, education level, and monthly personal income). The third section consisted of one open-ended question for the respondents to express any further opinions regarding organic fruit and vegetables. Two faculty members and four organic food consumers reviewed the scale structure and content for validity. A pilot study was carried out to establish the consistency of the questionnaire. Based on feedback from a pilot sample of 99 organic food shoppers, items were modified according to the reliability and validity analysis for the final instrument. Following the approach of Bagozzi and Yi [46], items with factor loadings lower than 0.5 or cross-loadings greater than 0.3 were deleted. Cronbach's $\alpha$ values of the variables ranged from 0.711 to 0.931 , indicating good reliability [47]. The final questionnaire, which included 19 items, was used to assess the four constructs. The 3-item scale in the subjective knowledge section was based on a scale by Pieniak et al. [4]. The 7-item scale in the behavioral beliefs section was adopted from Lea et al. [44]. The 6-item scale in the attitude section was based on studies by Ajzen [27] and Chen [39]. The 3-item scale measuring purchase intentions was based on a scale by Magnusson, Louise, and Hassan [45].

Table 2. Constructs and measurement.

\begin{tabular}{ccc}
\hline Constructs & Measurement & Sources \\
\hline Subjective knowledge & 3-item scale & Pieniak et al. [4] \\
Behavioral beliefs & 7-item scale & Lea et al. [44] \\
Attitudes & 6-item scale & Ajzen [27] and Chen [39]. \\
Purchase intentions & 3-item scale & Magnusson, Louise, and Hassan [45] \\
\hline
\end{tabular}

\subsection{Data Analysis}

The model was tested using structural equation modeling (SEM) with AMOS 26.0. Tests of measurement and structural invariance of the proposed model using data from the two groups were performed for comparison. SPSS 25.0 was used for descriptive statistical analysis and reliability testing [48]. A two-step approach was adopted for the SEM. First, to validate the developed constructs, the research model was estimated with confirmatory factor analysis (CFA) to ensure that all measurement items were loaded on their expected constructs, and the constructs were correlated in the analysis. Second, the structural model was later tested for the causal relationships between variables. Various fit indices were used to examine the structural models: The goodness-of fit index (GFI), adjusted goodness-of-fit index (AGFI), comparative fit index (CFI), non-normalized fit index (NNFI), incremental fit index (IFI), and root mean square error of approximation (RMSEA) [49]. The fit indices indicated good model fit when GFI > 0.8, CFI > 0.9, NNFI > 0.9, and RMSEA $<0.08[50,51]$. Lastly, a multi-group invariance analysis was performed on the structural model to assess group differences in the extent of paths (structural weight) between groups. Before beginning to estimate invariance models, a configural model was established. This initial model served as the baseline against all subsequent invariance tests.

Depending on the model and hypotheses to be tested, sets of parameters are put to restriction for analysis [43]. Since the use of $\Delta \chi 2$ has been criticized because of its sensitivity to sample size, the results for each invariance test are explained by the change in the CFI value $(\triangle \mathrm{CFI})$ as the index of difference in fit. Following Cheung and Rensvold's [52] 
suggestions, a model with all paths constrained to be equal across groups (the constrained model) was compared to the configural model with all paths freely estimated (the free model). If the $\Delta$ CFI $>0.01$ in favor of the free model, then group differences in the extent of the path exist; otherwise, the constrained model was preferred. One inference from group difference is that there is a moderating effect on causal relationships in the model, and this effect varies by group [53].

\section{Results}

\subsection{Quantitative Analysis}

Table 3 shows the descriptive statistics of the scale items of the study. The overall mean scores ranged from 3.06 to 4.05 . Because the maximum likelihood estimation procedures were used in this study, the normality assumption was tested for violation [51]. Following the guidelines of severe nonnormality (i.e., skewness $>3$ and kurtosis $>10$ ) proposed by Kline [54], the values in Table 3 were within the guidelines and could be regarded as normal for further analyses.

Table 3. Mean, standard deviation, skewness, and kurtosis of the scale items.

\begin{tabular}{|c|c|c|c|c|c|c|c|c|c|c|c|c|}
\hline & \multicolumn{3}{|c|}{ Overall $(N=871)$} & \multirow[b]{2}{*}{$\mathbf{K}$} & \multicolumn{3}{|c|}{$\begin{array}{l}\text { Labeled Organic } \\
\qquad(N=468)\end{array}$} & \multicolumn{5}{|c|}{ Organic $(N=403)$} \\
\hline & $\mathbf{M}$ & SD & Sk & & $\mathbf{M}$ & SD & Sk & $\mathbf{K}$ & $\mathbf{M}$ & SD & Sk & K \\
\hline SK1 & 3.40 & 0.904 & -0.037 & -0.297 & 3.38 & 0.909 & -0.109 & -0.144 & 3.42 & 0.898 & 0.052 & -0.481 \\
\hline SK2 & 3.11 & 0.961 & 0.113 & -0.268 & 3.10 & 0.965 & 0.138 & -0.248 & 3.12 & 0.957 & 0.085 & -0.266 \\
\hline SK3 & 2.70 & 1.080 & 0.309 & -0.417 & 2.77 & 1.146 & 0.306 & -0.585 & 2.63 & 0.993 & 0.239 & -0.281 \\
\hline BE1 & 3.79 & 0.942 & -0.378 & -0.324 & 3.60 & 0.980 & -0.310 & -0.231 & 4.02 & 0.845 & -0.307 & -0.922 \\
\hline BE2 & 4.11 & 0.884 & -0.751 & -0.020 & 3.99 & 0.930 & -0.616 & -0.213 & 4.25 & 0.806 & -0.881 & 0.203 \\
\hline BE3 & 3.78 & 0.969 & -0.309 & -0.622 & 3.64 & 1.014 & -0.246 & -0.585 & 3.95 & 0.888 & -0.279 & -0.944 \\
\hline BE4 & 4.04 & 0.883 & -0.662 & -0.014 & 3.92 & 0.932 & -0.622 & -0.071 & 4.18 & 0.796 & -0.624 & -0.327 \\
\hline BE5 & 3.93 & 0.924 & -0.440 & -0.428 & 3.84 & 0.957 & -0.495 & -0.161 & 4.03 & 0.875 & -0.304 & -1.091 \\
\hline BE6 & 3.80 & 0.915 & -0.308 & -0.391 & 3.69 & 0.960 & -0.310 & -0.275 & 3.92 & 0.846 & -0.196 & -0.889 \\
\hline BE7 & 3.97 & 0.945 & -0.566 & -0.221 & 3.96 & 0.957 & -0.719 & 0.139 & 3.99 & 0.933 & -0.451 & -0.847 \\
\hline AT1 & 3.68 & 0.941 & -0.490 & 0.140 & 3.58 & 1.011 & -0.403 & -0.184 & 3.79 & 0.839 & -0.500 & 0.547 \\
\hline AT2 & 3.47 & 0.945 & -0.084 & -0.260 & 3.40 & 1.016 & -0.224 & -0.304 & 3.56 & 0.849 & 0.328 & -0.701 \\
\hline AT3 & 3.73 & 0.939 & -0.549 & 0.169 & 3.66 & 0.993 & -0.534 & 0.022 & 3.82 & 0.866 & -0.494 & 0.230 \\
\hline AT4 & 3.54 & 0.906 & -0.170 & -0.147 & 3.45 & 0.966 & -0.147 & -0.164 & 3.65 & 0.819 & -0.067 & -0.406 \\
\hline AT5 & 3.77 & 0.909 & -0.500 & 0.052 & 3.70 & 0.973 & -0.498 & -0.012 & 3.84 & 0.824 & -0.399 & -0.163 \\
\hline AT6 & 3.74 & 0.976 & -0.493 & 0.012 & 3.70 & 1.009 & -0.608 & 0.216 & 3.78 & 0.936 & -0.307 & -0.403 \\
\hline PI1 & 3.21 & 0.959 & 0.004 & -0.328 & 3.14 & 0.993 & 0.017 & -0.366 & 3.30 & 0.911 & 0.036 & -0.305 \\
\hline PI2 & 3.29 & 0.946 & -0.073 & -0.311 & 3.19 & 0.970 & -0.087 & -0.310 & 3.32 & 0.914 & -0.028 & -0.338 \\
\hline PI3 & 3.17 & 0.975 & -0.117 & -0.325 & 3.07 & 1.004 & 0.037 & -0.307 & 3.23 & 0.929 & -0.284 & -0.218 \\
\hline
\end{tabular}

Notes: $\mathrm{M}=$ mean; $\mathrm{SD}=$ standard deviation; $\mathrm{Sk}=$ skewness; $\mathrm{K}=$ kurtosis.

The results showed that the certification-labeled group and the non-labeled group of organic food shoppers indicated average scores of 3.08 and 3.06, respectively, on a five-point Likert scale in terms of their subjective knowledge toward organic fruits and vegetables, results that suggest that organic food shoppers consider their subjective knowledge toward organic fruits and vegetables to be average in general. When analyzing the results at the item level, both of the first two questions regarding subjective knowledge (that is, "Compared with an average person, I know a lot about organic fruits and vegetables" and "I know a lot about how to judge/evaluate the quality of organic fruits and vegetables") received a higher score than the overall average score noted above for both labeled $\left(\operatorname{mean}_{\mathrm{L}}=3.38\right.$, 3.10 ) and non-labeled group $\left(\right.$ mean $\left._{N}=3.42,3.12\right)$. However, the third question regarding subjective knowledge ("People who know me consider me an expert in the field of organic fruits and vegetables") received a lower score than the overall average score noted above for both labeled and non-labeled groups $\left(\operatorname{mean}_{\mathrm{L}}=2.77, \operatorname{mean}_{\mathrm{N}}=2.63\right)$. 
Among the behavioral belief items, the items "Consuming (certification labeled) organic fruits and vegetables helps me stay healthy" $\left(\operatorname{mean}_{\mathrm{L}}=3.99\right.$, mean $\left._{\mathrm{N}}=4.25\right)$ and "Consuming (certification labeled) organic fruits and vegetables increases my control over my own health" $\left(\operatorname{mean}_{\mathrm{L}}=3.92\right.$, mean $\left._{\mathrm{N}}=4.18\right)$ were the highest-ranking questions in terms of scores for both groups. The mean scores for the attitude construct ranged from 3.47 to 3.77 for the overall samples, from 3.40 to 3.70 for the labeled group, and from 3.56 to 3.84 for the non-labeled group. The mean scores for the purchase intentions ranged from 3.17 to 3.29 for the overall samples, from 3.07 to 3.19 for the labeled group, and from 3.23 to 3.32 for the non-labeled group.

\subsection{Measurement Model}

The quality of the measurement model was assessed using CFA to validate the four model constructs. Construct reliability was initially evaluated using Cronbach's $\alpha$ reliability test. Fornell and Larcker [55] listed three measures by which to assess convergent validity. These are the item reliability of each measure, composite reliability of each construct, and the average variance extracted (AVE). To validate the developed constructs, the research model was estimated with CFA. In the testing model, all factor loadings were significant $(p<0.000)$, ranging from 0.92 to 0.50 (Table 4$)$. They thus met the threshold set by Hair et al. [42], indicating convergent validity at the item level.

Table 4. Summary of measurement scales.

\begin{tabular}{|c|c|c|c|c|c|c|c|c|c|}
\hline \multirow[b]{2}{*}{ Constructs/Items } & \multicolumn{3}{|c|}{ All } & \multicolumn{3}{|c|}{ Labeled Organic } & \multicolumn{3}{|c|}{ Organic } \\
\hline & FL & CR & AVE & FL & CR & AVE & FL & CR & AVE \\
\hline Subjective knowledge (SK) & & 0.876 & 0.703 & & 0.882 & 0.714 & & 0.865 & 0.681 \\
\hline SK1 & 0.63 & & & 0.78 & & & 0.81 & & \\
\hline SK2 & 0.84 & & & 0.92 & & & 0.90 & & \\
\hline SK3 & 0.63 & & & 0.83 & & & 0.76 & & \\
\hline Behavioral belief (BE) & & 0.927 & 0.646 & & 0.927 & 0.647 & & 0.927 & 0.644 \\
\hline BE1 & 0.56 & & & 0.74 & & & 0.75 & & \\
\hline BE2 & 0.62 & & & 0.79 & & & 0.77 & & \\
\hline BE3 & 0.67 & & & 0.83 & & & 0.79 & & \\
\hline $\mathrm{BE} 4$ & 0.73 & & & 0.84 & & & 0.86 & & \\
\hline BE5 & 0.72 & & & 0.86 & & & 0.84 & & \\
\hline BE6 & 0.67 & & & 0.82 & & & 0.82 & & \\
\hline BE7 & 0.55 & & & 0.74 & & & 0.78 & & \\
\hline Attitude (AT) & & 0.884 & 0.561 & & 0.905 & 0.615 & & 0.842 & 0.474 \\
\hline AT1 & 0.52 & & & 0.75 & & & 0.65 & & \\
\hline AT2 & 0.54 & & & 0.75 & & & 0.71 & & \\
\hline AT3 & 0.58 & & & 0.84 & & & 0.62 & & \\
\hline AT4 & 0.53 & & & 0.75 & & & 0.70 & & \\
\hline AT5 & 0.67 & & & 0.83 & & & 0.81 & & \\
\hline AT6 & 0.52 & & & 0.78 & & & 0.62 & & \\
\hline Purchase intention (PI) & & 0.891 & 0.734 & & 0.928 & 0.810 & & 0.852 & 0.680 \\
\hline PI1 & 0.83 & & & 0.87 & & & 0.97 & & \\
\hline PI2 & 0.87 & & & 0.92 & & & 0.96 & & \\
\hline PI3 & 0.50 & & & 0.91 & & & 0.50 & & \\
\hline
\end{tabular}

Notes: FL: Standardized factor loading; CR: Composite reliability; AVE: Average variance extracted.

The model with all factor loadings freely estimated across groups fit the model adequately: $\chi 2=646.020, \mathrm{df}=146, \mathrm{GFI}=0.925, \mathrm{AGFI}=0.903, \mathrm{CFI}=0.954, \mathrm{NNFI}=0.947$, and RMSEA $=0.063$. The fit indices indicated good model fit $(\mathrm{GFI}>0.8, \mathrm{CFI}>0.9, \mathrm{NNFI}>0.9$, and RMSEA < 0.08) $[50,51]$. The internal consistency figures also met the necessary criteria, with Cronbach's $\alpha$ and composite reliability scores all being above 0.7 [55] for both groups and the average variance extracted (AVE) being acceptable for all domains (Tables 4 and 5). Convergent validity is judged to be adequate when the average variance extracted equals or exceeds 0.5 [55]. As shown in Table 4, the convergent validity for the proposed con- 
structs of this study was adequate. The square correlation coefficients of any two variables were less than the AVE. In conclusion, the measurement scale demonstrated discriminant validity [55].

Table 5. Means, standard deviations, Cronbach's alpha, and correlations of the constructs.

\begin{tabular}{cccccc}
\hline & Mean (S.D.) & $\alpha$ & $\mathbf{1}$ & $\mathbf{2}$ & $\mathbf{3}$ \\
\hline All & & & & & \\
1 Subjective knowledge (SK) & $3.07(0.87)$ & 0.866 & & & \\
2 Behavioral belief (BE) & $3.92(0.77)$ & 0.926 & 0.36 & & \\
3 Attitudes (AT) & $3.66(0.74)$ & 0.883 & 0.52 & 0.55 & \\
4 Purchase intention (PI) & $3.21(0.86)$ & 0.883 & 0.62 & 0.42 & \\
$\quad$ Labeled Organic & & & & & \\
1 Subjective knowledge & $3.08(0.90)$ & 0.880 & & & \\
2 Behavioral belief & $3.81(0.80)$ & 0.926 & 0.36. & & \\
3 Attitudes & $3.58(0.82)$ & 0.906 & 0.46 & 0.46 & \\
4 Purchase intention & $3.14(0.93)$ & 0.929 & 0.57 & 0.57 & \\
$\quad$ Organic & & & & & \\
1 Subjective knowledge & $3.06(0.84)$ & 0.857 & & & \\
2 Behavioral belief & $4.05(0.71)$ & 0.925 & 0.39 & 0.60 \\
$\quad$ 3 Attitudes & $3.75(0.64)$ & 0.837 & 0.63 & 0.54 & \\
4 Purchase intention & $3.11(0.55)$ & 0.807 & 0.69 & 0.32 &
\end{tabular}

Notes: S.D.: Standard deviation; $\alpha$ : Cronbach's alpha.

\subsection{Structural Model}

Path analysis was used for hypothesis testing to determine the model validity. This study verified the causal relationships of hypotheses using SEM. SEM is a statistical practice that combines multiple regression and factor analysis to concurrently estimate a series of relationships between interrelated variables [42]. Using all 871 samples for analysis, the path analysis demonstrated that the revealed subjective knowledge significantly influences consumer behavioral beliefs $(\beta=0.37, p=0.002)$. In other words, the shoppers' subjective knowledge of organic produce positively influenced their behavioral beliefs regarding organic produce, thus supporting Hypothesis 1. Subjective knowledge also significantly influenced attitudes $(\beta=0.366, p=0.002)$. In other words, shoppers' subjective knowledge of organic produce positively influenced their attitudes toward their purchasing of organic produce, thus supporting Hypothesis 2. Subjective knowledge also significantly influenced purchase intentions $(\beta=0.447, p=0.002)$. In other words, shoppers' subjective knowledge of organic produce positively influenced their purchase intentions toward organic produce, thus supporting Hypothesis 3. Next, it was found that behavioral beliefs significantly affected attitudes $(\beta=0.421, p=0.002)$. In other words, shoppers' behavioral beliefs regarding organic produce positively influenced their attitudes toward their purchasing of organic produce, thus supporting Hypothesis 4. Finally, attitudes positively influenced purchase intentions $(\beta=0.334, p=0.002)$. In other words, shoppers' attitudes toward their purchasing of organic produce positively influenced their purchase intentions toward organic produce, supporting Hypothesis 5. The path results of the research model using pooled samples $(N=871)$ are shown in Figure 3. Table 6 shows the parameter estimates of the structural model analysis results. 


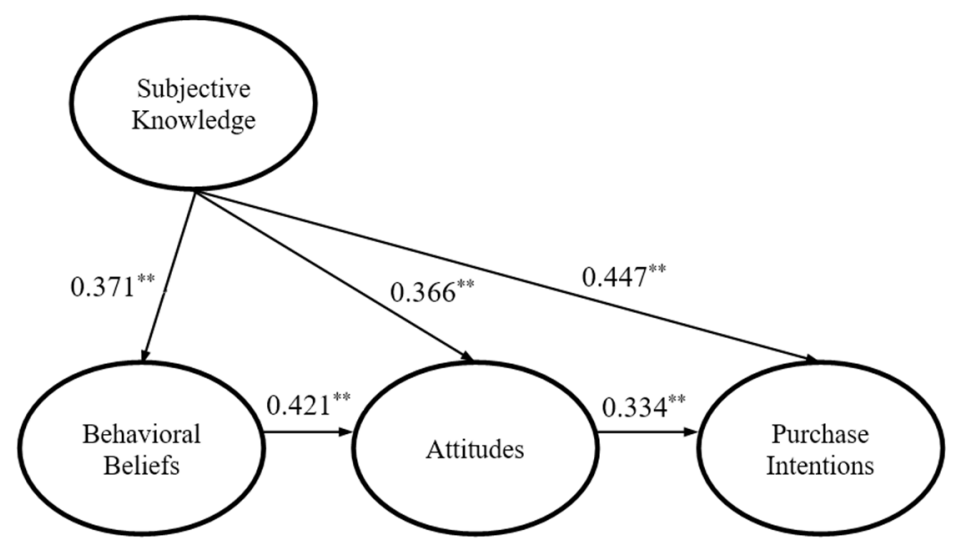

Figure 3. Path results of the research model using pooled samples $(N=871)$. Note: ${ }^{* *} p=0.002$.

Table 6. Parameter estimates of the structural model.

\begin{tabular}{|c|c|c|c|c|c|c|c|c|c|}
\hline \multicolumn{3}{|c|}{ Parameter } & \multicolumn{3}{|c|}{ Bias-Corrected } & \multicolumn{2}{|c|}{ Percentile } & \multirow{3}{*}{$\begin{array}{c}p \text {-Value } \\
0.002\end{array}$} & \multirow{3}{*}{$\begin{array}{c}\text { Hypothesis Testing } \\
\text { H1 supported }\end{array}$} \\
\hline & & & \multirow{2}{*}{$\begin{array}{c}\text { Estimate } \\
0.371\end{array}$} & \multirow{2}{*}{$\begin{array}{c}\text { Lower } \\
0.301\end{array}$} & \multirow{2}{*}{$\begin{array}{c}\text { Upper } \\
0.443\end{array}$} & \multirow{2}{*}{$\begin{array}{c}\text { Lower } \\
0.299\end{array}$} & \multirow{2}{*}{$\begin{array}{c}\text { Upper } \\
0.440\end{array}$} & & \\
\hline $\mathrm{BE}$ & $\leftarrow$ & SK & & & & & & & \\
\hline AT & $\leftarrow$ & SK & 0.366 & 0.300 & 0.436 & 0.296 & 0.432 & 0.002 & H2 supported \\
\hline PI & $\leftarrow$ & SK & 0.447 & 0.372 & 0.518 & 0.372 & 0.521 & 0.002 & H3 supported \\
\hline AT & $\leftarrow$ & $\mathrm{BE}$ & 0.421 & 0.345 & 0.495 & 0.347 & 0.495 & 0.002 & H4 supported \\
\hline PI & $\leftarrow$ & AT & 0.334 & 0.264 & 0.412 & 0.261 & 0.411 & 0.002 & H5 supported \\
\hline
\end{tabular}

Note. $\quad N=871$, bootstrap $=2000 . \quad \mathrm{BE}=$ behavioral belief; $\mathrm{SK}=$ subjective knowledge; $\mathrm{AT}=$ attitude; $\mathrm{PI}=$ purchase intention

In addition, in both the labeled and non-labeled groups, subjective knowledge positively influenced behavioral beliefs $\left(\beta_{\mathrm{L}}=0.36, p=0.002 ; \beta_{\mathrm{N}}=0.39, p=0.002\right)$, attitudes $\left(\beta_{\mathrm{L}}=0.30\right.$, $\left.p=0.002 ; \beta_{\mathrm{N}}=0.50, p=0.002\right)$, and purchase intentions $\left(\beta_{\mathrm{L}}=0.42, p=0.002 ; \beta_{\mathrm{N}}=0.51\right.$, $p=0.002$ ), as well as indirectly influencing attitudes and purchase intentions in both groups. In both the labeled and non-labeled groups, organic food shoppers' behavioral beliefs regarding organic produce positively influenced their attitudes toward their purchasing of organic produce $\left(\beta_{\mathrm{L}}=0.44, p=0.002 ; \beta_{\mathrm{N}}=0.394, p=0.002\right)$; as did shoppers' attitudes positively influence their purchase intentions toward organic produce $\left(\beta_{\mathrm{L}}=0.33, p=0.002 ; \beta_{\mathrm{N}}=0.27\right.$, $p=0.002)$. The standardized path coefficients and $\mathrm{R}^{2}$ values of the model of the two groups are presented in Figure 4, and the fit indices are presented in Table 7.

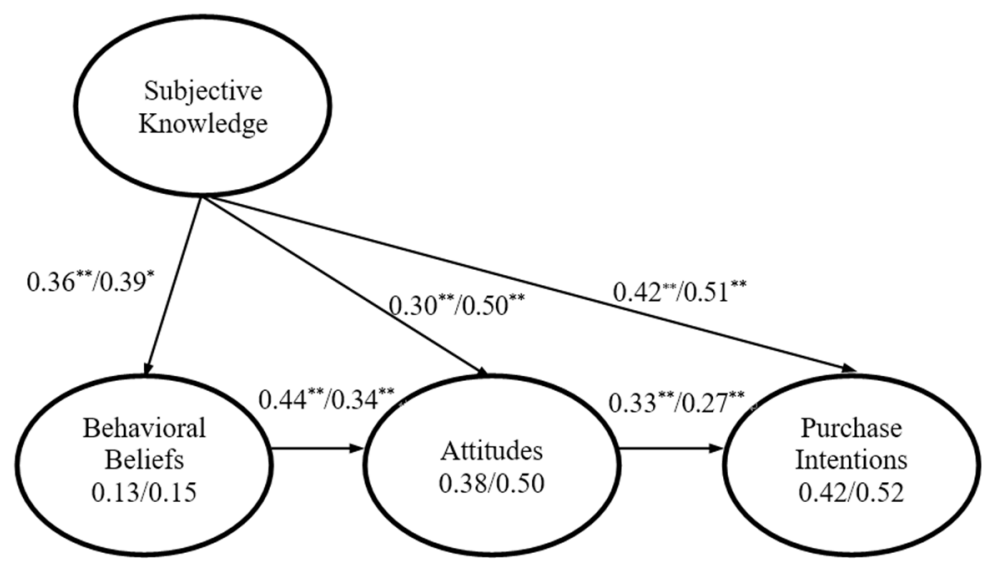

Figure 4. Path coefficients presented as the case of labeled/non-labeled organic. $R^{2}$ values are noted below the variables. Structural equation modeling results of the research model. Note: ${ }^{*} p<0.05$, ** $p<0.01$. 
Based on the results, the proposed model received considerable support, indicating that Hypothesis 1 to Hypothesis 5 are supported. Next, the hypothesized structural model was tested for group differences.

\subsection{Multi-Group Analysis}

Various multi-group analyses were performed using AMOS 26.0. The estimation for each analysis was performed using maximum likelihood and was based on a covariance matrix. Before conducting the multi-group analysis of structural invariance, pooled group data $(N=871)$ were examined for model fit. The fit indices indicated an adequate model-data fit (Table 6). These results indicated that the structural model was properly specified, that a proper solution was obtained, and that the solution fit the entire sample adequate.y The fit indices indicated good model fit (GFI $>0.8, \mathrm{CFI}>0.9, \mathrm{NNFI}>0.9$, and RMSEA < 0.08) [50,51].

Tests for the measurement and structural invariance were performed accordingly. The results for each invariance test were explained by the change in CFI. This model also fit the data well, with the fit indicators being as follows: $\chi 2=1149.092, d f=314, \chi 2 / d f=3.66$, $\mathrm{RMSEA}=0.055, \mathrm{GFI}=0.878, \mathrm{NNFI}=0.920$, and CFI $=0.926$. The $\Delta$ CFI between Model 1 and Model 3 was $0.011>0.010$ in favor of Model 1, indicating that at least one structural path was different in strength between the groups (Table 7). A path difference comparison between the two groups was further conducted for additional investigation.

Table 7. Fit indices for multi-group invariance tests.

\begin{tabular}{|c|c|c|c|c|c|c|c|c|}
\hline Test & $x^{2}$ & $d f$ & $p$ & GFI & AGFI & NNFI & RMSEA & CFI \\
\hline Pooled samp & 55.091 & 147 & 000 & 0.924 & 0.902 & 0.946 & 0.063 & 0.954 \\
\hline Labeled o & 518. & 147 & .000 & 0.892 & 0.860 & & 0.074 & 0.943 \\
\hline Organic & 490.929 & 147 & 0.000 & 0.889 & 0.856 & 0.919 & 0.076 & 0.930 \\
\hline $\begin{array}{c}\text { Configural invariance } \\
\text { (baseline model) (Model 1) }\end{array}$ & 1009.067 & 294 & 0.000 & 0.890 & 0.858 & 0.927 & 005 & 0.937 \\
\hline $\begin{array}{l}\text { Measurement weight } \\
\text { invariance (Model 2) }\end{array}$ & 1139.860 & 309 & 0.000 & 0.879 & 0.851 & 0.920 & 0.056 & 0.928 \\
\hline $\begin{array}{l}\text { Structural weight } \\
\text { invariance (Model 3) }\end{array}$ & 1149.092 & 314 & 0.000 & 0.878 & 0.852 & 0.920 & 0.055 & 0.926 \\
\hline
\end{tabular}

Notes: Configural invariance (factor patterns equal); measurement weight invariance (factor loadings equal); structural weight invariance (structural relation among latent variables equal).

Results of the unstandardized parameter estimates comparison between the two groups are shown in Table 8 . The results demonstrate that there was a significant difference between the labeled and non-labeled groups in the path coefficient from behavioral beliefs to attitudes; therefore, Hypothesis 6-4 is supported.

Table 8. Parameter estimates comparison of the structural model.

\begin{tabular}{|c|c|c|c|c|c|c|}
\hline & Organic & & Labeled Orga & & & Hrnethese \\
\hline & $\begin{array}{l}\text { Unstandardized } \\
\text { Estimates }\end{array}$ & $p$ & $\begin{array}{l}\text { Unstandardized } \\
\text { Estimates }\end{array}$ & $p$ & $z$-Score & Testing \\
\hline $\mathrm{BE} \leftarrow \mathrm{SK}$ & 0.339 & 0.000 & 0.368 & 0.000 & 0.416 & $\begin{array}{l}\text { H6-1 not } \\
\text { supported }\end{array}$ \\
\hline $\mathrm{AT} \leftarrow \mathrm{SK}$ & 0.376 & 0.000 & 0.321 & 0.000 & -0.792 & $\begin{array}{l}\text { H6-2 not } \\
\text { supported }\end{array}$ \\
\hline $\mathrm{PI} \leftarrow \mathrm{SK}$ & 0.623 & 0.000 & 0.508 & 0.000 & -1.224 & $\begin{array}{l}\text { H6-3 not } \\
\text { supported }\end{array}$ \\
\hline $\mathrm{AT} \leftarrow \mathrm{Be}$ & 0.294 & 0.000 & 0.462 & 0.000 & $2.323^{* *}$ & $\begin{array}{c}\text { H6-4 } \\
\text { supported }\end{array}$ \\
\hline $\mathrm{PI} \leftarrow \mathrm{AT}$ & 0.438 & 0.000 & 0.377 & 0.000 & -0.548 & $\begin{array}{l}\text { H6-5 not } \\
\text { supported }\end{array}$ \\
\hline
\end{tabular}

Note. $\mathrm{BE}=$ behavioral belief; SK = subjective knowledge; AT = attitude; PI = purchase intention; ${ }^{* *} p<0.01$. 
However, no significant differences in the path coefficient from subjective knowledge to behavioral beliefs, from subjective knowledge to attitudes, from subjective knowledge to purchase intentions, and from attitudes to purchase intentions were observed among the two groups; therefore, Hypotheses 6-1, 6-2, 6-3, and 6-5 are not supported. In summary, Hypothesis 6 is partially supported.

\subsection{Open-Ended Question}

Feedback collected from the open-ended question further assisted in the interpretation of the quantitative data. Out of the total 871 effective surveys that were collected, 173 respondents (19.86\%) answered the open-ended question asking if they would like to express any further opinions regarding organic produce (i.e., fruits and vegetables). Several themes emerged from shoppers' feedback regarding this open-ended question, including themes regarding health aspects (43), pricing concerns (33), government certification and promotion (31), credibility issues (13), being supportive in general (10), a lack of knowledge (9), social aspects (7), lifestyle (7), environmental protection (5), accessibility (4), taste (4), and others (9).

\subsubsection{Health Aspects}

Regarding the respondents' feedback on health aspects of organic produce, they generally recognized organic fruits and vegetables as being "healthy", "natural", "free of pesticides", "decreasing the level of food additives in my diet", and "a good choice for family elders and relatives", in addition to making statements such as "I buy them for my children and husband because it is free of pesticides and safe" and "I recommend eating organic fruits and vegetables." However, other statements included the following: "I have heard people say that organic vegetables are not very healthy because they are hydroponics and are not grown in soil" and "organic is not necessarily healthy; focusing on lifestyle and a veggie diet is healthier."

\subsubsection{Pricing Concerns}

Regarding the respondents' feedback on pricing issues, they generally considered organic fruits and vegetables to be more expensive than conventional produce, making statements about them such as "too expensive"; "I can only consume organic produce sometimes, I cannot afford it for all my meals"; "the price is higher, so organic produce is not convenient for students to buy"; "hope it can be cheaper"; "not easy to grow so the cost is higher, resulting in higher prices, but it feels healthy and safe"; "prices vary too much", "the supply is too limited with higher prices"; "the price is too high and this impacts my buying intentions"; "organic fruits and vegetables are pricy but have many advantages; however, I buy less considering my personal financial limitation"; and "a scam." Since the respondents generally considered organic fruits and vegetables to be more expensive than conventional produce, this led them to question the worth and value, as well as the credibility and authenticity, of organic produce.

\subsubsection{Government Certification and Promotion}

Regarding the respondents' feedback concerning government certification and promotion, they generally would like to see more promotion of organic fruits and vegetables, as well as the stricter implementation of the regulation and certification process from the government. Statements on this subject included the following: "further promotion of the knowledge and common sense of organic vegetables is needed"; "information regarding organic certification is limited, so the government should promote and educate the general public for further awareness of the subject"; "the government should consider this issue as being one of great importance because organic certification is something very important to public health"; "government should implement the regulations more strictly"; "many hypermarkets don't have clear organic certification labeling"; "the certification logo does not have a very discreet identification"; "I hope that organic fruits and vegetables can 
be more popular, so the certification process should be more transparent to gain further support from the public"; "I hope that certification labeling will be implemented more strictly, because if the price is high but the quality is low, it would be a great deception to the consumer; most of those in the market are untruthful"; "people seems to have only a vague idea of the organic concept, and the certification process also needs to be strengthened"; "labeling should be more clearly marked"; "now organic fruits and vegetables are claimed everywhere, but it is intriguing to know whether such claims are legitimate or not; in any case, we really hope wholeheartedly that someday a world of pure organics will come"; "the government should control the utilization of fertilizers and pesticides more aggressively, because no matter what, health is most important"; "Taiwan's organic certification is only for reference, while the EU's regulation standards are worth borrowing from"; and "organic certification labeling is often not appropriate, as many fake their certification."

\subsubsection{Credibility Issues}

Some respondents reflected that they feel that organic produce has credibility issues: "I want to purchase organic fruits and vegetables, but the ones I get are not necessarily authentic"; "I hope those are the ones that I can trust, with quality, planted by them so they know the importance of the process." Some of the respondents also questioned the organic certification itself: "Are those bad looking ones sold in the traditional market that look like they were produced without using pesticides not counted as organic produce? Is it only those very expensive ones marketed as certified organic fruits and vegetables that can be counted as organic produce?"; "The identification of organic fruits and vegetables is untruthful. It's very difficult to really do it properly. It is not that you spend more money and they provide you something genuine that justifies the price"; "According to news reports of the results of random sampling inspections, the percentage of detected pesticide residues on organic produce is not low, so I worry that organic is a scam"; "I hope that organic fruits and vegetables are genuinely organic, because sometimes there were negative reports that resulted in people distrusting the validity of organic produce."

\subsubsection{Lack of Knowledge}

The respondents also reflected on their shortage of knowledge regarding organic fruits and vegetables: "I feel that I cannot know exactly if organic fruits and vegetables are genuine organic fruits and vegetables." "I feel it is healthier but in reality I don't know." "I feel that the word organic sounds healthier, so I purchase it." "I hope to know more about organic fruits and vegetables." "It tastes OK, and I hope to know more about organic fruits and vegetables." "I don't really know what is organic."

\subsubsection{Social Aspects}

The respondents also mentioned some social issues: "The involvement of big corporate companies (chain store systems) thoroughly commercializes the organic food business. Please give the (conventional) organic food business a simple, clean, and natural space for survival. This business should be a highly specialized profession, but now it doesn't look like one." "I think how you cook and prepare the food matters more, but the organic concept can help the survival of small premium agricultural businesses." "I hope the stores can be bigger and provide more variety like an organic food supermarket." "Heartless business people make the supply of organic fruits and vegetables rare and expensive." "Due to Taiwan's pseudo demand, one must pay high costs to get high quality. Maybe this is a marketing scam or bad judgment." "Unless the production was certified through reliable certification and sold through direct marketing, it is hard to screen qualified middleman, so even certified vegetables cannot guarantee product safety and reliability. Many suppliers no longer pay attention to quality and safety after they have gotten certified; the only thing they care about is market profit." 


\subsubsection{Lifestyle}

Some respondents mentioned their lifestyle related to organic food consumption and purchasing in the open-ended question: "I cook and eat organic food every day, and my parents-in-law also like to eat it." "My mom often buys organic produce for the family to eat, so we are kind of used to eating organic food." "I often purchase organic produce, so it's becoming a habit; I encourage everyone to eat organic food." "I consume organic food sometimes." "I usually buy organic produce for my kids." "I buy organic produce for my family." "I buy organic produce when I pass by a market."

\subsubsection{Environmental Protection}

Some respondents reflected on the connection between organic agriculture and the environment: "Organic fruits and vegetables are not only good for human health, it is also important that organic produce is Mother Nature friendly." "The advantage of going organic is that there is no need to worry about pesticide residues. Also, it is environmentally friendly and causes no pollution. However, the quality of organic food doesn't necessarily improve as a result of that; it has nothing to do with its nutritional values or taste. The disadvantage of going organic is that organic agriculture has pest control problems; therefore, the production rate can't be high, resulting in higher costs and prices of the products. For the consumers, it is hard to tell if the price has been driven up by companies or not. Consumers worry about purchasing fake organic products, and thus organic suppliers should certify their products with high standards so as to protect consumers' rights." "Organic fruits and vegetables don't necessarily equate to healthy fruits and vegetables. It is more important to focus on their impact on the environment, including a clear certificate of origin and how it is planted." "According to tracking studies, the production rate of organic agriculture is no less than that of conventional agriculture. Sustainable agriculture is feasible only when farming lands are not damaged by pesticides." "We should have confidence in advocating global environmental protection, with an emphasis on going organic. Go! Go! Go! Everyone!"

\subsubsection{Accessibility}

Some respondents also expressed their wishes for increased accessibility for organic food: "I hope to have more channels to purchase organic produce." "I really want to buy organic produce, but I cannot do that all the time." "There should be more places that sell organic products." "Eating healthy organic produce is more reliable than eating produce with pesticide residues; however, trust and convenience in purchasing organics are even more important."

\section{Discussion}

The contribution of this study consists of a theoretical understanding backed by empirical results. Taiwanese shoppers generally prefer convenient, healthy, high-quality food and beverages $[24,33,34]$. Within the region, Taiwan has the highest per capita spending on food and beverages, with grocery spending accounting for approximately 30 percent of total consumer spending in 2020 [56]. Certified organic produce is grown without chemical pesticides, fertilizers, or hormones [12], making such produce among the most sought-after food products on the market. Since 2009, Taiwan has applied labeling regulations for organic agricultural products. However, consumers have remained skeptical about the authentication mechanism for certifying organic foods [24,33,34]. Among other agricultural product certifications, including GAP, TAP, and Organic Agricultural Products in Taiwan [24], this study sought to examine whether and to what extent the organic certification labeling makes a difference in today's organic food shoppers' organic food buying process. A conceptual model was tested for validity, and group differences between the labeled and non-labeled groups were investigated using multi-group structural equation modeling (SEM) techniques. 
The literature shows that credence attributes, such as organic, affect consumers' attraction to products, mainly in a positive direction $[5,18,57]$. However, through this study, it was found that the relationship between the behavioral beliefs and attitudes of organic produce shoppers would be significantly influenced by certification labeling. In addition, in both the labeled and non-labeled groups, the associations between behavioral beliefs and attitudes observed in this study were consistent with the results of previous organic food studies $[4,33,34,41,58,59]$. Subjective knowledge positively influenced behavioral beliefs, attitudes, and purchase intentions, as well as indirectly influencing attitudes and purchase intentions in both groups. When analyzing the results at the item level, both the first two questions regarding subjective knowledge (that is, "Compared with an average person, I know a lot about organic fruits and vegetables" and "I know a lot about how to judge/evaluate the quality of organic fruits and vegetables") received a higher score than the overall average score noted above for both the labeled and non-labeled groups. This indicated that organic food shoppers do consider themselves to know somewhat more about organic produce when compared with other average people, in addition to indicating that they know somewhat more about how to judge and evaluate the quality of organic produce. However, the third question regarding subjective knowledge ("People who know me, consider me an expert in the field of organic fruit and vegetables") received a lower score for both the labeled and non-labeled groups, indicating that organic food shoppers do not think that people who know them consider them to be an expert in the field of organic produce. Through the open-ended question, the respondents reflected their shortage of knowledge regarding organic fruits and vegetables.

Major themes emerging from the feedback to the open-ended question regarding organic fruits and vegetables were health aspects, pricing concerns, government certification and promotion, and credibility issues. In our study, organic food shoppers generally held positive beliefs that consuming organic fruits and vegetables would help them stay healthy and increase their overall control over their health. However, their concerns over higher organic produce prices led them to question the worth and value, as well as the credibility and authenticity, of organic produce. As one respondent noted, if the price of organic produce is high but the expected quality is low, or even if it is not a genuine organic product, consumers would feel greatly deceived. Some respondents reflected their worries that organic certification is only a marketing scam. They expressed concern that suppliers may overlook the standards once their products are certified. In reality, the government of Taiwan demands that farmers, processors, traders, and every other operation in the organic production chain must be inspected and certified each year [12]. This ensures compliance with the organic production requirements of the market.

\section{Conclusions}

As consumer knowledge of organic production increases over time, consumer intentions to purchase and consume organic produce also increase. However, some consumers are still not fully aware of the whole concept of organic production. Feedback collected via the open-ended question supported that the respondents would like to see more promotion of organic produce from the government; also, respondents looked for thorough implementation of certification regulations by the government for the credibility and authenticity of organic produce. We therefore suggest that related government authorities and other market actors in the organic sector should: 1. Inform people about the beneficial aspects of organic fruits and vegetables; 2 . ensure thorough implementation of simplified and transparent organic regulations; and 3. inform the public about related government certification occurrences and activities.

Funding: This research received no external funding.

Institutional Review Board Statement: Not applicable.

Informed Consent Statement: Not applicable. 


\section{Data Availability Statement: Not applicable.}

Acknowledgments: I would like to express my heartfelt thanks to the experts who have taken the time to review this article and provide valuable comments.

Conflicts of Interest: The author declares no conflict of interest.

\section{References}

1. Tonkin, E.; Wilson, M.W.; Coveney, J.; Webb, T.; Meyer, S.B. Trust in and through labelling-A systematic review and critique. Br. Food J. 2015, 117, 318-338. [CrossRef]

2. Kihlberg, I.; Johansson, L.; Langsrud, Ø.; Risvik, E. Effects of information on liking of bread. Food. Qual. Prefer. 2005, 16, 25-35. [CrossRef]

3. Lee, H.-J.; Yun, Z.-S. Consumers' perceptions of organic food attributes and cognitive and affective attitudes as determinants of their purchase intentions toward organic food. Food. Qual. Prefer. 2015, 39, 259-267. [CrossRef]

4. Pieniak, Z.; Aertsens, J.; Verbeke, W. Subjective and objective knowledge as determinants of organic vegetables consumption. Food. Qual. Prefer. 2010, 21, 581-588. [CrossRef]

5. Poelman, A.; Mojet, J.; Lyon, D.; Sefa-Dedeh, S. The influence of information about organic production and fair trade on preferences for and perception of pineapple. Food Qual. Prefer. 2008, 19, 114-121. [CrossRef]

6. Fernqvist, F.; Ekelund, L. Credence and the effect on consumer liking of food-A review. Food. Qual. Prefer. 2014, 32, 340-353. [CrossRef]

7. Ness, M.R.; Ness, M.; Brennan, M.; Oughton, E.; Ritson, C.; Ruto, E. Modelling consumer behavioural intentions towards food with implications for marketing quality low-input and organic food. Food. Qual. Prefer. 2010, 21, 100-111. [CrossRef]

8. Alexa, L.; Apetrei, A.; Sapena, J. The COVID-19 lockdown effect on the intention to purchase sustainable brand. Sustainability 2021, 13, 3241. [CrossRef]

9. Meixner, O.; Katt, F. Impact of COVID-19 on Consumer Food Safety Perceptions-A Choice-Based Willingness to Pay Study. Sustainability 2020, 12, 7270. [CrossRef]

10. Grebitus, C.; Bodo, S.; Michele, V. The roles of human values and generalized trust on stated preferences when food is labeled with environmental footprints: Insights from Germany. Food Policy 2015, 52, 84-91. [CrossRef]

11. Czeczotko, M.; Gorska-Warsewicz, H.; Laskowski, W.; Rostecka, B. Towards Sustainable Private Labels in an Autonomous Community during COVID-19-Analysis of Consumer Behavior and Perception on the Example of Tenerife. Sustainability 2021, 13, 7467. [CrossRef]

12. Qi, X.; Yu, H.; Ploeger, A. Exploring influential factors including COVID-19 on green food purchase intentions and the intentionbehaviour gap: A qualitative study among consumers in a Chinese context. Int. J. Environ. Res. Public Health 2020, 17, 7106. [CrossRef] [PubMed]

13. Sacchi, A.; Catozzi, D.; Boietti, E.; Bert, F.; Siliquini, R. COVID-19 Lockdown and self-perceived changes of food choice, waste, impulse buying and their determinants in Italy: QuarantEat, a cross-sectional study. Foods 2021, 10, 306. [CrossRef]

14. Smiglak-Krajewska, M.; Wojciechowska-Solis, J. Consumer versus organic products in the COVID-19 pandemic: Opportunities and barriers to market development. Energies 2021, 14, 5566. [CrossRef]

15. Xie, X.; Huang, L.; Li, J.J.; Zhu, H. Generational differences in perceptions of food health/risk and attitudes toward organic food and game meat: The case of the COVID-19 crisis in China. Int. J. Environ. Res. Public Health 2020, 17, 3148. [CrossRef] [PubMed]

16. Council of Agriculture. Taiwan's Organic Agricultural Development Policy and Its Measures. 2019. Available online: http: / / eng.coa.gov.tw/content_view.php?catid=2502414\&hot_new=2501117 (accessed on 1 June 2021).

17. Dabbert, S.; Lippert, C.; Zorn, A. Introduction to the special section on organic certification systems: Policy issues and research topics. Food Policy 2014, 49, 425-428. [CrossRef]

18. Grunert, K.G.; Hieke, S.; Wills, J. Sustainability labels on food products: Consumer motivation, understanding and use. Food Policy 2014, 44, 177-189. [CrossRef]

19. Aitken, R.; Watkins, L.; Williams, J.; Kean, A. The positive role of labelling on consumers' perceived behavioural control and intention to purchase organic food. J. Clean. Prod. 2020, 255, 120334. [CrossRef]

20. Kuan, M.-Y.; Wang, S.-Y.; Wang, J.-H. Investigating the Association between Farmers' Organizational Participation and Types of Agricultural Product Certifications: Empirical Evidence from a National Farm Households Survey in Taiwan. Sustainability 2021, 13, 9429. [CrossRef]

21. Liao, P.-A.; Chang, H.-H.; Chang, C.-Y. Why is the food traceability system unsuccessful in Taiwan? Empirical evidence from a national survey of fruit and vegetable farmers. Food Policy 2011, 36, 686-693. [CrossRef]

22. Liu, C.-C. Food Safety and Traceability of Agricultural Products. Available online: https://ap.fftc.org.tw/article/1401 (accessed on 20 April 2021).

23. Lee, W.C. Organic farming needs regulating. Taipei Times. 2014. Available online: http://www.taipeitimes.com/News/ editorials/archives/2014/10/03/2003601131 (accessed on 20 December 2014).

24. Wang, G.T.; Yueh, H.P. Optimistic bias, food safety cognition, and consumer behavior of college students in Taiwan and main land China. Foods 2020, 9, 1588. [CrossRef]

25. Organic Agriculture Promotion Act. Available online: https://info.organic.org.tw/5903/ (accessed on 15 October 2020). 
26. PISA 2018 Result. Available online: https:/ / www.oecd.org/pisa/publications/pisa-2018-results.htm (accessed on 21 November 2020).

27. Ajzen, I. Attitudes and Persuasion; Oxford University Press: Oxford, UK, 2012; pp. 367-393.

28. Hussain, I.; Rahman, S. Integrating factors influencing consumers' Halal products purchase: An application of Theory of reasoned action. J. Int. Food Agribus. Mark. 2016, 28, 35-58. [CrossRef]

29. Paul, J.; Modi, A.; Patel, J. Predicting green product consumption using theory of planned behavior and reasoned action. J. Retail. Consum. Serv. 2016, 29, 123-134. [CrossRef]

30. Qi, X.; Ploeger, A. Explaining Chinese consumers' green food purchase intentions during the COVID-19 pandemic: An extended theory of planned behavior. Food 2021, 10, 1200. [CrossRef]

31. Nosi, C. Sustainable consumption in organic food buying behavior: The case of quinoa. Br. Food J. 2020, 122, 976-994. [CrossRef]

32. Tarkianinen, A.; Sundqvist, S. Subjective norms, attitudes and intentions of Finnish consumers in buying organic food. Br. Food J. 2005, 107, 808-822. [CrossRef]

33. Teng, C.-C.; Wang, Y.-M. Decisional factors driving organic food consumption generation of consumer purchase intentions. $\mathrm{Br}$. Food J. 2015, 117, 1066-1081. [CrossRef]

34. Teng, C.-C.; Lu, C.-H. Organic food consumption in Taiwan: Motives, involvement, and purchase intention under the moderating role of uncertainly. Appetite 2016, 105, 95-105. [CrossRef]

35. Magkos, F.; Arvaniti, F.; Zampelas, A. Organic food: Buying more safety or just peace of mind? A critical review of the literature Crit. Rev. Food Sci. Nutr. 2006, 46, 23-56. [CrossRef]

36. McEachern, M.G.; Willock, J. Producers and consumers of organic meat: A focus on attitudes and motivations. Br. Food J. 2004, 106, 534-552. [CrossRef]

37. Fillion, L.; Arazi, S. Does organic food taste better? A claim substantiation approach. Nutr. Food Sci. 2002, 32, 153-157. [CrossRef]

38. Saba, A.; Messina, F. Attitudes towards organic foods and risk/benefit perception associated with pesticides. Food. Qual. Prefer. 2003, 14, 637-645. [CrossRef]

39. Chen, M.-F. Attitude toward organic foods among Taiwanese as related to health consciousness, environmental attitudes, and the mediating effects of a healthy lifestyle. Br. Food J. 2009, 111, 165-178. [CrossRef]

40. Brucks, M. The effects of product class knowledge on information search behavior. J. Consum. Res. 1985, 12, 1-16. [CrossRef]

41. Aertsens, J.; Mondelaers, K.; Verbeke, W.; Buysse, J.; Van Huylenbroeck, G. The influence of subjective and objective knowledge on attitude, motivations and consumption of organic food. Br. Food J. 2011, 113, 1353-1378. [CrossRef]

42. Hair, J.F.; Black, W.C.; Babin, B.J.; Anderson, R.E.; Tatham, R.L. Multivariate Data Analysis, 6th ed.; Pearson Prentice Hall: Upper Saddle Rivers, NJ, USA, 2006.

43. Byrne, B.M. Testing for multigroup invariance using AMOS graphics: A road less traveled. Struct. Equ. Model. 2004, 11, 272-300. [CrossRef]

44. Lea, E.; Worsley, A. The factors associated with the belief that vegetarian diets provide health benefits. Asia Pac. J. Clin. Nutr. 2003, 12, 296-303.

45. Magnusson, M.; Louise, M.; Hassan, M. Modeling the factors affecting rural consumers' purchase of organic and free-range produce-A case study of consumers' from the Island of Arran in Scotland, UK. Food Policy 2010, 35, 130-139.

46. Bagozzi, R.P.; Yi, Y. On the evaluation of structural equation models. J. Acad. Mark. Sci. 1988, 16, 74-94. [CrossRef]

47. Nunnally, J.C.; Bernstein, I.H. Psychometric Theory, 3rd ed.; McGraw-Hall Inc.: New York, NY, USA, 1994.

48. IBM. IBM SPSS Statistics; IBM Corporation: Armonk, NY, USA, 2021.

49. Anderson, J.C.; Gerbing, D.W. Structural equation modeling in practice: A review and recommended two-step approach. Psychol. Bull. 1988, 103, 411. [CrossRef]

50. Doll, W.J.; Xia, W.; Torkzadeh, G. A confirmatory factor analysis of the end-user computing satisfaction instrument. MIS Q. 1994, 18, 453-461. [CrossRef]

51. Curran, P.J.; West, S.G.; Finch, J.F. The robustness of test statistics to nonnormality and specification error in confirmatory factor analysis. Psychol. Methods 1996, 1, 16. [CrossRef]

52. Cheung, G.W.; Rensvold, R.B. Evaluating goodness-of-fit indexes for testing measurement invariance. Struct. Equ. Model. 2002, 9 , 233-255. [CrossRef]

53. Cheung, G.W.; Rensvold, R.B. Testing factorial invariance across groups: A reconceptualization and proposed new method. $J$. Manag. 1999, 25, 1-27. [CrossRef]

54. Kline, R.B. Principles and Practice of Structural Equation Modeling, 3rd ed.; Guilford press: New York, NY, USA, 2011.

55. Fornell, C.; Larcker, D.F. Structural equation models with unobservable variables and measurement error: Algebra and statistics. J. Mark. Res. 1981, 18, 382-388. [CrossRef]

56. Annual Expenditure on Food, Beverage, and Tobacco per Household in Taiwan from 2010 to 2020. Available online: https:/ /www statista.com/statistics/922694/taiwan-expenditure-on-food-beverage-tobacco-per-household/ (accessed on 19 September 2020).

57. Liu, R.; Hoefkens, C.; Verbeke, W. Chinese consumers' understanding and use of a food nutrition label and their determinants. Food Qual. Prefer. 2015, 41, 103-111. [CrossRef]

58. Zagata, L. Consumers' beliefs and behavioural intentions towards organic food. Evidence from the Czech Republic. Appetite 2012, 59, 81-89. [CrossRef]

59. Zhang, B.; Fu, Z.; Huang, J.; Wang, J.; Xu, S.; Zhang, L. Consumers' perceptions, purchase intention, and willingness to pay a premium price for safe vegetables: A case study of Beijing, China. J. Clean. Prod. 2018, 197, 1498-1507. [CrossRef] 